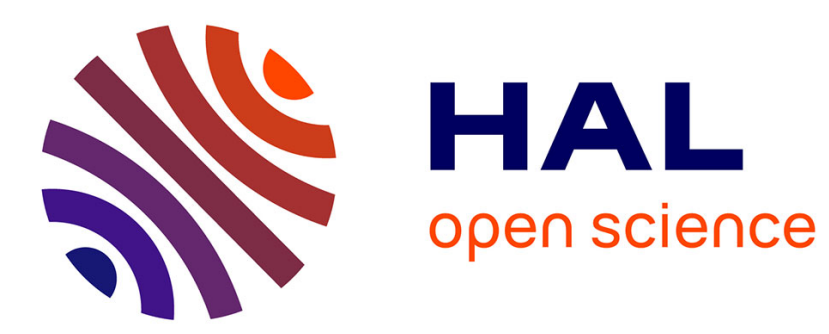

\title{
Influence of natural adsorbates of magnesium oxide on its reactivity in basic catalysis
}

Damien Cornu, Hugo Petitjean, Guylène Costentin, Hazar Guesmi, Jean-Marc Krafft, Helène Lauron-Pernot

\section{- To cite this version:}

Damien Cornu, Hugo Petitjean, Guylène Costentin, Hazar Guesmi, Jean-Marc Krafft, et al.. Influence of natural adsorbates of magnesium oxide on its reactivity in basic catalysis. Physical Chemistry Chemical Physics, 2013, 15 (45), pp.19870-19878. 10.1039/C3CP53624F . hal-00911519

\section{HAL Id: hal-00911519 https://hal.science/hal-00911519}

Submitted on 20 May 2015

HAL is a multi-disciplinary open access archive for the deposit and dissemination of scientific research documents, whether they are published or not. The documents may come from teaching and research institutions in France or abroad, or from public or private research centers.
L'archive ouverte pluridisciplinaire HAL, est destinée au dépôt et à la diffusion de documents scientifiques de niveau recherche, publiés ou non, émanant des établissements d'enseignement et de recherche français ou étrangers, des laboratoires publics ou privés. 


\title{
Influence of natural adsorbates of magnesium oxide on its reactivity in basic catalysis
}

\author{
Damien Cornu ${ }^{1,2, \#}$, Hugo Petitjean ${ }^{1}$, ${ }^{2, \S}$, Guylène Costentin ${ }^{1,2}$, Hazar Guesmi, ${ }^{1,2 \S}$ Jean-Marc \\ Krafft $^{1,2}$ and Hélène Lauron-Pernot ${ }^{1,2 *}$ \\ ${ }^{1}$ UPMC - Université Pierre et Marie Curie, Laboratoire de Réactivité de Surface, UMR 7197, 3 rue \\ Galilée 94200 Ivry sur Seine, France \\ ${ }^{2}$ CNRS, UMR 7197, Laboratoire de Réactivité de Surface, 3 rue Galilée 94200 Ivry sur Seine, France. \\ * helene.pernot@upmc.fr
}

\section{Abstract}

Solid materials possessing basic properties are naturally covered by carbonates and hydroxyl group. Those natural adsorbates modify their chemical reactivity. This article aims to specifically evidence the role of surface carbonates and hydroxyls in basic heterogeneous catalysis on $\mathrm{MgO}$. It compares the catalytic behaviors of hydroxylated or carbonated $\mathrm{MgO}$ surfaces for two types of reactions: one alkene isomerization and one alcohol conversion (hept-1-ene isomerization and 2-methyl-3-butyn-2-ol conversion). Catalysis experiments showed that carbon dioxide adsorption poisons the catalyst surface and the DRIFT-DFT combination showed that the nature of active sites in the two reactions differs. On the reverse, partial hydroxylation of the surface enhances activity for both reactions. Interestingly hept1-ene isomerization gives a volcano curve for the conversion as a function of hydroxyl coverage. Calculations of the electronic structure of magnesium oxide surface show that neither Lewis basicity nor Brønstedt basicity of the surface defects (steps for example) are enhanced by hydroxylation. Meanwhile $\mathrm{CO}_{2}$ adsorption followed by IR spectroscopy shows that (110) and (111) unstable planes are strongly basic and are stabilized by partial surface hydroxylation. That result could explain the volcano curve obtained for the evolution of alkene isomerisation as a function of hydroxyl coverage.

\footnotetext{
present address : $\quad \S$ Institut Charles Gerhardt Montpellier, UMR 5253 CNRS-UM2-ENSCM-UM1, Matériaux Avancés pour la Catalyse et la Santé (MACS), Ecole Nationale Supérieure de Chimie, 8 rue de l'Ecole Normale, 34296 Montpellier Cedex 5, France

\# Fritz-Haber-Institut der MPG, Department of Chemical Physics, Faradayweg 4-6, 14195 Berlin, Germany
} 


\section{Introduction}

Using basic catalysts is of growing interest due to the need of transforming biomass derivates. The basic properties of a solid were traditionally measured either by following the adsorption of acidic molecules on the basic surfaces mainly by IR spectroscopy ${ }^{1-5}$, calorimetry ${ }^{6,1}$ and thermoprogrammed methods ${ }^{2,1}$ or by using model reaction. ${ }^{7-9}$ During the ten past years experimental and theoretical works have been performed to better define the basic properties of inorganic solids. ${ }^{8,3,10,11}$

Studying the adsorption equilibrium of a probe molecule gives insights on the basic properties from a thermodynamic point of view. ${ }^{12}$ In that respect those static methods provide a basic strength that is not necessarily correlated with the basicity expressed in catalysis, the overall rate of a catalytic reaction occurring on basic sites. ${ }^{8}$ To distinguish that basicity expressed in catalysis from the standard thermodynamic basicity, we called it "kinetic basicity". ${ }^{13}$ The other important conclusion concerns the type of basic site involved in base-catalyzed reactions: Brønsted $v s$ Lewis. In the first step of mechanisms reactants usually deprotonate and stabilize on an acid-base pair, so the ability for the site to initiate the reaction is correlated to its deprotonation ability, its Brønsted basicity, which may differ from the ability of the surface to adsorb Lewis acids like $\mathrm{CO}_{2}$. Therefore $\mathrm{CO}_{2}$ adsorption experiments should be correlated with results of basic catalysis only with careful and explicit hypotheses.

$\mathrm{CO}_{2}$ and water naturally adsorb on basic solids like $\mathrm{MgO}$. In previous works, resulting adsorbates, carbonates and hydroxyls, were extensively described through dual experimental-theoretical approaches with a peculiar focus on the coordination mode and the way to probe it. ${ }^{13,3}$ From a catalytic point of view it was shown that partially hydroxylated $\mathrm{MgO}$ surfaces are more reactive in the conversion of 2-methyl-3-butyn-2-ol $(\mathrm{MBOH})$ conversion than bare surfaces while they are less 
thermodynamically basic. ${ }^{8}$ Could this beneficial effect of the $\mathrm{OH}$ weak base be generalized to the other natural weakly basic adsorbate, the carbonate?

The aim of the present study is to compare the reactivity of basic active sites present on partially hydroxylated and carbonated $\mathrm{MgO}$ surfaces for $\mathrm{MBOH}$ conversion and hept-1-ene isomerization. Basic reactivity of the partially carbonated surfaces was evaluated with $\mathrm{MBOH}$ model reaction as it was done with partially hydroxylated surfaces previously. To describe the kinetic basicity of the surfaces further, we also considered a second model reaction, hept-1-ene isomerisation (Figure 1), which is supposed to be more sensitive to strong sites than $\mathrm{MBOH}$ conversion. Indeed, alkenes are less easily deprotonated than alcohols: the proton affinity of the conjugated bases is lower for alcohol $\left(1563 \mathrm{~kJ} . \mathrm{mol}^{-1}\right.$ for methanol $\left.{ }^{14}\right)$ than for alkene $\left(1636 \mathrm{~kJ} \cdot \mathrm{mol}^{-1}\right.$ for the propene $\left.{ }^{15}\right)$. Therefore, the number of sites deprotonating alcohol should be higher than for alkene. ${ }^{16}$ Moreover, these two model reactions differ also from a kinetic point of view. On one hand, for clean $\mathrm{MgO}$, the rate of the $\mathrm{MBOH}$ conversion is not limited by the deprotonating step, ${ }^{17}$ whereas, for the alkene isomerization, deprotonation is claimed to be the rate determining step according to experimental data based on the kinetic isotope effect. ${ }^{18}$ On the other hand, one recent modelling study has shown that, depending on the kind of active sites, the activation energy for the second step (migration of the proton back to the alkene) could be higher than for the first step. ${ }^{19}$ Keeping in mind this interrogation, the link between thermodynamic basicity and kinetic basicity has to be questioned for the two model reactions.

\section{Insert figure 1}

The present study of $\mathrm{MgO}$ basicity combine catalysis with model reactions, DRIFT characterization of adsorption sites with $\mathrm{CO}_{2}$ probe molecule, and DFT modelling of adsorption sites. Magnesium oxide is prepared by a classical precipitation method followed by a treatment under vacuum at $1273 \mathrm{~K}$ to stabilize the surface. In the catalysis reactor or in the DRIFT cell MgO surface was firstly cleaned up 
with an in situ high temperature treatment (1023 K), secondly hydroxylated or carbonated upon water or carbon dioxide adsorption and finally heated at controlled temperature under inert gas to be partially dehydroxylated or decarbonated. The resulting surface was partially hydroxylated or carbonated and ready to be evaluated in the model catalytic reactions. The identification of active sites involved in each reaction is then proposed taking into account the calculated desorption temperature of water ${ }^{20}$ and carbon dioxide from the defects (steps, corners, kinks and divacancies) of the stable (100) plane as well as from the unstable (110) and (111) planes. $^{3}$ Moreover, the influence of the partial coverage of the surface by $\mathrm{OH}$ groups on the Brønsted and Lewis basicity of the surface is studied by means of periodic DFT calculations of the electronic structure of magnesium oxide surface. IR studies of $\mathrm{CO}_{2}$ adsorption on partially hydroxylated or carbonated surfaces are used to probe the presence of the (110) and (111) unstable planes.

\section{Experimental section}

\subsection{Preparation of the catalyst.}

MgO sample was prepared from $\mathrm{Mg}(\mathrm{OH})_{2}$ precursor obtained by precipitation from $\mathrm{Mg}\left(\mathrm{NO}_{3}\right)_{2}$ (Aldrich, 99.99\%) and ammonium hydroxide (Aldrich, 99\%) as precipitating agent, according to a previously described procedure ${ }^{21}$. The hydroxide sample was finally treated in vacuum $\left(10^{-3}\right.$ Torr $)$ up to $1273 \mathrm{~K}$ (ramp $1 \mathrm{~K} \cdot \mathrm{min}^{-1}$ ) and maintained at this temperature for $2 \mathrm{~h}$. This procedure is used to stabilize $\mathrm{MgO}$ surface towards the effect of further thermal treatments.

\subsection{In situ thermal treatments.}

In order to control the carbonate or hydroxyl group surface coverage, the operating conditions reported in Figure 2 were processed in situ on the catalyst just before catalytic tests and IR measurements. During the pretreatment phase, the sample was cleaned up for $2 \mathrm{~h}$ at $1023 \mathrm{~K}$ under nitrogen flow (Air Liquide, nitrogen $\mathrm{U}>99.995 \%$ pure) at $20 \mathrm{~cm}^{3} \cdot \mathrm{min}^{-1}$, then cooled down to $323 \mathrm{~K}$.

To obtain the carbonated surfaces, during the treatment phase, the sample was first contacted with carbon dioxide (Air Liquide, Alphagaz, $>99.9 \%$ pure) diluted in nitrogen (5\% in a 20 
$\mathrm{cm}^{3} \cdot \mathrm{min}^{-1}$.flow) for $15 \mathrm{~min}$. Then, it was once again heated at the intermediate temperature temp $(473 \mathrm{~K}<$ temp $<1073 \mathrm{~K})$ in a nitrogen flow $\left(20 \mathrm{~cm}^{3} \cdot \mathrm{min}^{-1}\right)$ for $2 \mathrm{~h}$.

To obtain the hydroxylated surfaces, as described previously ${ }^{8}$, the same pretreatment i.e. treatment sequences was used, except that carbon dioxide flow was replaced by a $\mathrm{H}_{2} \mathrm{O} / \mathrm{N}_{2}$ flow $(840 \mathrm{~Pa}$ for $\mathrm{H}_{2} \mathrm{O}$ in $20 \mathrm{~cm}^{3}$. $\mathrm{min}^{-1}$ flow) for $10 \mathrm{~min}$ at $373 \mathrm{~K}$.

In the following, the degree of carbonatation or hydroxylation of the sample is quantified by the indication of the final desorption temperature "temp".

\section{Insert Figure 2}

\subsection{IR measurements}

DRIFT spectra were recorded on a Brüker IFS $66 \mathrm{~V}$ spectrometer in the $4000-600 \mathrm{~cm}^{-1}$ range $\left(4 \mathrm{~cm}^{-1}\right.$ resolution, 256 scans/spectrum) using a Thermo Spectra-Tech high temperature cell. All spectra were converted into Kubelka-Munk units after subtraction of the spectrum recorded on dehydrated $\mathrm{KBr}$ sample. All spectra are recorded in situ after the pretreatment procedure described in section and the cooling down of the sample to $333 \mathrm{~K}$.

\subsection{Hept-1-ene isomerisation}

Hept-1-ene isomerisation was followed in an automated differential flow microreactor. For each experiment, $40 \mathrm{mg}$ of catalyst was deposited on porous glass, in the centre of a $10 \mathrm{~mm}$-i.d. $\mathrm{U}$ quartz tube. The reaction temperature of $333 \mathrm{~K}$ was controlled within $\pm 0.1 \mathrm{~K}$ by a thermocouple located by the catalyst. The desired hept-1-ene partial pressure was obtained by mixing a liquid flow of hept-1-ene $\left(0.3 \mathrm{~g} \cdot \mathrm{h}^{-1}\right)$ and a gas flow of nitrogen $\left(45 \mathrm{~cm}^{3} \cdot \mathrm{min}^{-1}\right)$. The resulting WHSV for hept-1-ene is $7.5 \mathrm{~h}^{-1}$ and the W/F ratio (catalyst weight/ total gas rate flow) is 0.015 g.h. $\mathrm{L}^{-1}$. Both liquid and gas flows were set by Bronkhorst mass flow controllers and mixed in a controlled evaporator mixer. Reaction products were analysed every 366 s using a Perichrom 2100 chromatograph equipped with a FID detector and a Varian capillary CP WAX 57 CB column. 
After each kind of treatment, the sample was cooled down to $333 \mathrm{~K}$ and contacted with hept-1ene diluted in nitrogen $(3 \mathrm{~mol} . \%)$ at $333 \mathrm{~K}$. The first analysis of the reaction products is made $120 \mathrm{~s}$ after the admission of hept-1-ene on the sample. The absence of diffusional limitations was checked by varying the mass of the catalyst and the reactant flow.

Because hept-1-ene and hept-2-ene are the only products detected, catalytic data are expressed in terms of conversion only. The hept-1-ene was converted into $\mathrm{Z}$ and $\mathrm{E}$ hept-2-ene. Average ratio $\mathrm{Z}$ hept-2-ene/E hept-2-ene was around 2 and did not vary in the different experiments. This value is common for basic surfaces. $^{22}$ The partial pressure of each product $\mathrm{P}_{\mathrm{i}}$ was calculated from chromatographic measurements using the appropriate response coefficient. The conversion $\tau$ is thus given by: $\tau=\frac{\mathrm{P}_{1}^{\circ}-\mathrm{P}_{1}}{\mathrm{P}_{1}^{\circ}}$, with $\mathrm{P}_{1}$ the partial pressure of hept-1-ene in the outlet mixture and $\mathrm{P}_{1}^{\circ}$ the initial hept-1-ene partial pressure.

\subsection{MBOH conversion.}

$\mathrm{MBOH}$ reaction was followed in an automated differential flow microreactor. For each experiment, 20 $\mathrm{mg}$ of catalyst was deposited on porous glass, in the centre of a $10 \mathrm{~mm}$-i.d. U quartz tube. The reaction temperature of $393 \mathrm{~K}$ was controlled within $\pm 1 \mathrm{~K}$ by a thermocouple located by the catalyst. The desired $\mathrm{MBOH}$ partial pressure $(1.8 \mathrm{kPa})$ was obtained by bubbling nitrogen $\left(100 \mathrm{~cm}^{3} \cdot \mathrm{min}^{-1}\right)$ in liquid $\mathrm{MBOH}$ at $293 \mathrm{~K}$. The resulting WHSV for $\mathrm{MBOH}$ is $16 \mathrm{~h}^{-1}$ and the W/F ratio (catalyst weight/ total gas rate flow) is $3.3310^{-3}$ g.h.L $\mathrm{L}^{-1}$. Reaction products were analyzed every $120 \mathrm{~s}$ using a Varian micro gas chromatograph equipped with a catharometric detector and a CP WAX $52 \mathrm{CB}$ column. The MBOH was converted only through the basic pathway, giving acetone and acetylene. ${ }^{17}$

\subsection{Computational details}

\subsubsection{Methods.}

All calculations were performed using ab-initio plane-wave pseudopotential approach as implemented in $\operatorname{VASP}^{23,24}$. The generalized gradient approximation exchange-correlation functional of 
Perdew and Wang PW91 ${ }^{25}$ was chosen to perform the periodic DFT calculations with reliable accuracy on the convergence criterions. The one electron wave function was developed on a basis set of plane waves and the interaction between the core and the valence electrons is described by the projector augmented waves (PAW) approach. The selected description of the oxygen atomic core allows a good convergence on the energy for a cut-off of $400 \mathrm{eV}$. The convergence criterion for the electronic selfconsistent cycle was fixed to $10^{-6} \mathrm{eV}$ per supercell. Geometry optimizations were performed within a conjugate-gradient algorithm until the convergence criterion on forces $\left(10^{-2} \mathrm{eV} . \AA^{-1}\right)$ was reached. A dipolar correction along the perpendicular to the slab was applied in order to remove the effect of electrostatic interaction between the slab and its periodic images along the $z$ axis. The adsorption energy of acids (methanol or but-1-ene) on the $\mathrm{MgO}$ surfaces was calculated as:

$\mathrm{E}_{\mathrm{ads}}(0 \mathrm{~K})=\mathrm{E}_{\text {acid/surf }}-\left(\mathrm{E}_{\text {surf }}+\mathrm{E}_{\text {free-acid }}\right)$ eq. 1

Where $\mathrm{E}_{\text {surf }}$ represents the energy of bare surface, $\mathrm{E}_{\text {free-acid }}$ is the energy of gaseous acid and $\mathrm{E}_{\text {acid/surf }}$ that of the adsorbed system.

\subsubsection{Surfaces.}

The $\mathrm{MgO}$ surfaces were represented with the models already used in previous works:

- $\mathrm{MgO}(100)$ surface terrace (T) and surface defects such as monatomic steps (S1), diatomic steps (S2), corners (C3), divacancies (D), and kinks (K). ${ }^{20,26}$

- $\mathrm{MgO}(110)$ and $\mathrm{MgO}(111)$ surfaces. $^{3}$

\section{Results and discussion}

\subsection{Catalytic activity of the carbonated magnesium oxide}

The $\mathrm{MgO}$ sample was in situ carbonated with the procedure from the experimental part and, directly afterwards, studied in both model reactions. Figure 3 shows the conversion of $\mathrm{MBOH}$ and hept-1-ene as a function of desorption temperature (temp) after the carbonatation of the surface.

\section{Insert Figure 3}


For both reactions, the conversion level remains quite low under a limit temperature temp and rises for higher temp values. The limit temperature temp is between 500 and $600 \mathrm{~K}$ for $\mathrm{MBOH}$ conversion and between 700 and $750 \mathrm{~K}$ for hept-1-ene isomerisation.

Considering that the higher the temp value (thus the lower the carbonate coverage), the higher the reactivity, it can be concluded for both reactions that $\mathrm{CO}_{2}$ poisons the basic reactivity of magnesium oxide. Interestingly, the main difference between the two reactions is that the active sites are released from $\mathrm{CO}_{2}$ between 500 and $600 \mathrm{~K}$ for $\mathrm{MBOH}$ conversion and between 700 and $750 \mathrm{~K}$ for hept-1-ene isomerisation.

Thus, despite carbonates are, as hydroxyls groups, weak bases, they behave differently on $\mathrm{MgO}$ surfaces, at least concerning $\mathrm{MBOH}$ conversion. Indeed, in a previous work, hydroxyls groups were shown to be very active in $\mathrm{MBOH}$ conversion despite their weak basic strength. ${ }^{8}$ This discrepancy between the influence of carbonate and hydroxyl on the basic reactivity led us to examine more deeply the nature of $\mathrm{MgO}$ active sites in those two model reactions.

\subsection{Conversion of hept-1-ene on hydroxylated magnesium surfaces}

In order to verify whether the beneficial influence of hydroxyl observed for the $\mathrm{MBOH}$ conversion can be generalized to other base-catalyzed reactions, the influence of hydroxyl coverage on $\mathrm{MgO}$ surface was evaluated in the hept-1-ene conversion. The conversion obtained for this reaction is given in Figure 4 as a function of the desorption temperature (temp).

Insert Figure 4

This graph shows two distinct domains:

- For temp $<750 \mathrm{~K}$, conversion rises with temp. Therefore, one can assume that hydroxyl group exhibits a poisoning effect.

- $\quad$ For temp $>750 \mathrm{~K}$, conversion decreases when temp rises. 
It must then be concluded that the effect of the hydroxyl coverage on the conversion is not as simple as the effect of carbonate coverage since it depends on the nature of the reactant.

Those different behaviors on carbonated and hydroxylated surfaces can be rationalized with a description of the $\mathrm{MgO}$ surfaces at a molecular scale for each treatment temperature. This valuable data is brought in the following analysis combining DFT calculations and IR spectroscopy.

\subsection{Nature of the active sites for the carbonated magnesium oxide surfaces}

\subsubsection{Description of the carbonated surfaces}

In a recent work combining experimental and theoretical approaches, ${ }^{3}$ we have investigated the interactions of $\mathrm{CO}_{2}$ with regular sites of $\mathrm{MgO}$ (100), (111) and (110) surfaces and with defect sites of $\mathrm{MgO}$ (100), steps, corners, kinks, and divacancies. The results are summarized in Table 1. The calculated frequencies and desorption temperatures were correlated with experimental IR measurements on carbonated $\mathrm{MgO}$ surface for various temperatures of treatment as in the present work. That work led to the conclusion that most of the carbonates are desorbed from $\mathrm{MgO}$ surface between 673 and $873 \mathrm{~K}$. Only strongly adsorbed tridentate species desorb above $873 \mathrm{~K}$, as observed on the mono and diatomic steps of the (100) plane for example. Calculations were performed, with the same thermodynamic model, to estimate the coverage on the monoatomic step at various temperatures. From those calculations, the carbonates fully cover the edges below $103 \mathrm{~K}$, partially desorb between $103 \mathrm{~K}$ and $520 \mathrm{~K}$, but the last of them remain stable up over $873 \mathrm{~K}$.

\section{Insert Table 1}

Insert figure 5

\subsubsection{Correlation with catalytic data}

First of all, it must be recalled from Figure 3 that: 
- $\mathrm{CO}_{2}$ poisons the $\mathrm{MgO}$ catalytic activity

- the release of active sites is not obtained at the same temperature (temp) for the two reactions

- the conversion is stable within the range of experimental error for the high temp values in both reactions. It infers that the active sites must be located on a surface stable until $1023 \mathrm{~K}$.

That last statement implies that the active sites cannot be located on (111) and (110) planes because those surfaces are less stable than the (100) planes and reconstruct at temperatures lower than $900 \mathrm{~K} \cdot{ }^{27,28,3,29}$ The stability of such planes is widely discussed in the literature and seems to strongly depend on the structure of the crystal and on the atmospheric conditions. ${ }^{30}$ According to our recent experimental results, ${ }^{3}$ the carbonate species on the (110) planes disappear at a temperature lower than the desorption temperature predicted with atomistic modelling. That phenomenon was assigned to the disappearance of the (110) planes themselves at a temperature temp between $673 \mathrm{~K}$ and $873 \mathrm{~K}$.

In hept-1-ene isomerization, the results show that the active sites should be free from carbonate for a desorption temperature between 700 and $750 \mathrm{~K}$. Moreover, the stability of the hept-1-ene conversion after $750 \mathrm{~K}$ suggests that the active sites are mainly located on defects of the most stable (100) planes. Calculated desorption temperatures (Figure 5) indicate that those active sites in hept-1ene isomerization could be corners, kinks and divacancies of the (100) plane because they are freed from $\mathrm{CO}_{2}$ for desorption temperatures calculated between 722 to $820 \mathrm{~K}$.

In $\mathrm{MBOH}$ conversion, the active sites are released for desorption temperature values between 500 and $600 \mathrm{~K}$ (Figure 3). At those temperatures, all the considered sites are fully covered by carbonates except the steps, for which the carbonate coverage passes from $\theta=2 / 3$ to $\theta=1 / 3 \mathrm{ML}$ at a desorption temperature predicted around $518 \mathrm{~K}$. As a consequence we propose that the active sites for $\mathrm{MBOH}$ conversion are the free $\mathrm{MgO}$ pairs present on the partially carbonated steps.

From catalysis experiments and $\mathrm{CO}_{2}$ desorption modelling, we proposed different active sites for the two reactions we studied on carbonated $\mathrm{MgO}$. As each reaction involves a first deprotonating 
step, the reaction rate may depend on the deprotonation ability of each reactant towards the various sites available on the surface. In order to understand the difference between the two reactions, we investigated the geometric and energetic properties of each site giving them the ability to deprotonate alcohols and alkenes by DFT calculation.

\subsubsection{Strength of the basic sites of MgO towards alcohol and alkene}

To evaluate the strength of the $\mathrm{MgO}$ basic sites, we chose acidic probe molecules that can represent the deprotonation of the two reactants elegantly: methanol for the alcohol and but-1-ene for the hept-1-ene. Structure of adsorption were optimized, and the adsorption energies and the distance between hydrogen and the adjacent atom (carbon or oxygen) are gathered in Table 2. Results for the deprotonation of $\mathrm{MeOH}$ on (100) defects are depicted from ${ }^{26}$. The main optimized geometries of but1-ene adsorbed on various defects of the $\mathrm{MgO}(100)$ are shown in Figure 6.

\section{Insert table 2.}

\section{Insert Figure 6}

From a trend analysis, the adsorption of the two acids on $\mathrm{MgO}$ surfaces follows the same rule, that have already been observed with water and $\mathrm{MeOH}^{20,26}$ and can be schematically described as: the less coordinated the $\mathrm{O}_{\mathrm{LC}}$ oxide surface ion (with LC for "low coordinated" and $\mathrm{L}=3$, 4, or 5 for, respectively, three, four or five -fold coordinated oxide), the more exothermic the adsorption.

In the case of the alkene, we found that the deprotonated but-1-ene was likely to spontaneously reprotonate on steps. This result slightly differs from the work from Wang et $\mathrm{al}^{19}$ in which the deprotonated alkene was a little stabilized $(0.02 \mathrm{eV})$ compared to the physisorbed alkene on steps. The difference between the two results could be induced by the use of different slabs and convergence criteria. Furthermore, the difficulty for alkenes to deprotonate on steps is in line with our proposition of active sites for hept-1-ene isomerization: experimental activation of the hept-1-ene requires a 
desorption temperature at which corners, divacancies or kinks are released from $\mathrm{CO}_{2}$ because freeing steps is not enough.

In the case of the alcohol, the deprotonation process may occur on any surface sites, except on terraces. On the steps, the carbonate coverage determines the ability of the oxide to deprotonate. When the coverage is $2 / 3$ or $1 \mathrm{ML}$, methanol cannot be deprotonated because no $\mathrm{Mg}_{4 \mathrm{C}}$ cation is available to stabilize the alcoolate ion but methanol can be deprotonated with a coverage of $1 / 3$ (Figure 7). That result is consistent with the previous results reported in section 3.3.2: partially carbonated steps could exhibit active sites in $\mathrm{MBOH}$ conversion (free $\mathrm{Mg}_{4 \mathrm{C}} \mathrm{O}_{4 \mathrm{C}}$ pair).

Insert figure 7.

\subsection{Role of hydroxyls groups.}

\subsubsection{Main hypothesis}

As shown in Figure 4, partially hydroxylated $\mathrm{MgO}$ surfaces catalyze hept-1-ene isomerization in a different way than carbonated surfaces do:

- A maximum of activity is observed for a desorption temperature around $750 \mathrm{~K}$

- The conversion value obtained for that desorption temperature is higher than the one obtained in the same conditions for carbonated surfaces.

Nevertheless, it must be noticed that the clean surfaces obtained after desorption at $1023 \mathrm{~K}$ give the same conversion level in hept-1-ene isomerization whether the surfaces were carbonated or hydroxylated before the desorption pretreatment. Consistently the specific surface area of the material remains unaffected after a hydroxylation or a carbonatation cycle. Those two results show that the hydroxylation and carbonatation treatments are reversible, as pointed out in previous papers ${ }^{13}$. For that reason our catalytic results cannot be interpreted by the restructuration observed by Hattori et $\mathrm{al}^{31}$ where the $\mathrm{MgO}$ surface was thermally activated in another way than ours, without the preliminary high temperature pretreatment that stabilizes the oxide surface. 
Catalytic results on carbonated surfaces give insights on the relationship between Lewis basicity and kinetic basicity of the sites because $\mathrm{CO}_{2}$ is considered as a probe of basic Lewis site. Those results suggest that the basic sites necessary to deprotonate hept-1-ene are stronger, on a Lewis scale, than those able to deprotonate an alcohol. Thus we may propose three hypothesis to explain why a maximum of activity is observed for hept-1-ene isomerisation on hydroxylated surfaces while it is not the case for $\mathrm{MBOH}$ conversion: ${ }^{8}$

i) On partially hydroxylated surface, a concerted mechanism can take place associating an $\mathrm{OH}$ protonating the alkene and a neighboring oxide ion deprotonating the alkene (Figure 8). Such a mechanism was proposed by Hoq et al. ${ }^{32}$ for H-D exchange of an alkane molecule on hydroxylated $\mathrm{MgO}$ surface. Nevertheless, some previous studies using deuterated alkenes have shown that no protonic exchange occurs between the surface and the alkene at $333 \mathrm{~K}$ : the alkene isomerizes through a deprotonationprotonation process involving the same proton, ${ }^{33,34}$ which is incompatible with the mechanism proposed Figure 8.

ii) The $\mathrm{OH}$ groups enhance the thermodynamic basicity of neighbouring $\mathrm{Mg}^{2+}-\mathrm{O}^{2-}$ pairs released by partial dehydroxylation. In that case the isomerization of alkene would be speeded up because the reaction is reported to be kinetically determined by the deprotonation step ${ }^{18}$.

iii) Upon dehydroxylation, new unstable sites are created that disappear upon further increase of the desorption temperature.

The ii) hypothesis validity is examined in the following section by means of DFT analyses.

Insert figure 8

\subsubsection{Evaluation of the thermodynamic basicity of partially hydroxylated sites}


We examined the adsorption of but-1-ene on the (100) monoatomic step and on the kink without and within partial hydroxylation to see how a hydroxyl adsorbed close to a dehydroxylated $\mathrm{Mg}^{2+}-\mathrm{O}^{2-}$ pair modify the deprotonation ability of the pair towards an alkene.

\section{Insert table 3 \\ Insert figure 9}

The results show that partial hydroxylation of the surface does not increase its deprotonating ability towards the but-1-ene.The alkene adsorb on dehydroxylated steps and kinks with low adsorption energies, and partial hydroxylation of the defects does not modify those adsorption energies. That behavior sharply differs from what was observed for the adsorption of alcohol: ${ }^{26}$ upon hydroxylation of the sites, alcohol adsorption is significantly modified because the adsorption occurs with an important contribution of H-bonding, which is not the case with the alkene.

In the alkene case, the stabilisation of the deprotonated carbanion species by the $\mathrm{Mg}^{2+}$ ion is very low because the negative charge delocalizes on the three carbon atoms of the allylic structure and because the hydrogen atoms around that negative charge hinder the approach of the adsorption site. Therefore, the Lewis basicity of the hydroxylated and non hydroxylated steps has to be analyzed to understand that difference. We analyzed thus the influence of the hydroxylation on the charge of surface ions and on the electric potential of the step from electronic calculations.

a) The charge on the oxygen ion: as one can consider that an anion with a larger charge may adsorb more easily a proton from an acid. Bader charge analyses ${ }^{35}$ do not evidence any effect of $\mathrm{OH}$ groups on the basicity of neighbouring oxide ions (non reported results).

b) The electric potential around the oxide: it is known that the basicity of an oxide is not only related to the charge of the oxygen ion but also to the Madelung potential generated by the network of charges ${ }^{36-39}$. Therefore, it is interesting to analyze the 
effect of the addition of an $\mathrm{OH}$ group on the surface and to verify whether that may alter the electric potential around the oxide. In figure 9 are represented the electric field maps of the $\mathrm{MgO}$ step surface before and after $\mathrm{OH}$ adsorption. As attested by the non changed contrast of the free $\mathrm{O}$ surface in the adsorbed $\mathrm{H}_{2} \mathrm{O}$ neighbourhood (see arrows), no change occurs after the addition of an $\mathrm{OH}$ group on $\mathrm{MgO}$ surface.

\section{Insert Figure 10}

Finally, from those electronic structure analyses on the step with different hydroxyl coverage, it is worth to note that no sharp differences were evidenced between the hydroxylated and nonhydroxylated surfaces.

To sum up that section, DFT modelling of but-1-ene adsorption did not show any influence of the surface partial hydroxylation on the deprotonation of the alkene. Presently no solid argument supports the hypothesis ii). However, without DFT modelling of the isomerization mechanism, it cannot be definitely excluded that $\mathrm{OH}$ groups enhance the kinetic basicity of $\mathrm{MgO}$ surfaces because a recent paper has proposed that the alkene isomerization on $\mathrm{MgO}$ might process with another rate determining step than the deprotonation. ${ }^{19}$

\subsubsection{Transient creation of strong basic sites}

The other hypothesis is that partially hydroxylated surfaces have more active sites than bare ones because partial hydroxylation may generate and stabilize new unstable sites that are more active than the stable ones but that disappear upon further increase of the desorption temperature. Those transient active sites could be located on unstable planes like (110) and (111), which reconstruct into more stable and less active (100) planes upon heating. ${ }^{28}$ We have already shown that $\mathrm{CO}_{2}$ is a good tool to investigate nature of the exposed $\mathrm{MgO}$ planes. ${ }^{3}$ Here we follow the adsorption of $\mathrm{CO}_{2}$ with DRIFT to study the influence of partial hydroxylation on unstable $\mathrm{MgO}$ planes. 
The partially hydroxylated surfaces were prepared with various hydroxylation coverages following the usual in situ thermal procedure. Then $\mathrm{CO}_{2}$ was adsorbed on the $\mathrm{MgO}$ surface and desorbed at $673 \mathrm{~K}$. The corresponding surface configurations were analysed with infra-red spectroscopy.

Figure 11 shows the DRIFT spectra of magnesium oxide after $\mathrm{CO}_{2}$ addition on a partially hydroxylated (solid green line) and dehydroxylated (dashed blue line) surface.

\section{Insert Figure 11}

Two main observations can be made from those spectra:

- The sample adsorbs more $\mathrm{CO}_{2}$ when the adsorption occurs on partially hydroxylated magnesium oxide. That was already observed by Kwon and Park. ${ }^{4} \mathrm{OH}$ groups seem to enhance the ability of $\mathrm{MgO}$ surface to adsorb $\mathrm{CO}_{2}$.

- The proportion of (110) planes to (100) defects is at its highest for the hydroxylated sample treated at $773 \mathrm{~K}$. That proportion is evaluated from the ratio of signals characteristic for each carbonate species: bands between 1350 and $1600 \mathrm{~cm}^{-1}$ were assigned to carbonates adsorbed on the (110) planes and bands at lower and higher frequencies were assigned to carbonates adsorbed on (100) defects. The ratio of intensities of those two groups of bands is at its highest for $\mathrm{CO}_{2}$ adsorbed on sample dehydroxylated at $773 \mathrm{~K}$.

That result indicates that hydroxylation helps to the transient stabilisation of the (110) planes, in agreement with literature data. ${ }^{27,40,41}$ The proportion of (110) planes decreases when the dehydroxylation process goes further, consistently with the unstability of those planes without help of surface hydroxyls.

The adsorption energies of methanol and but-1-ene on those unstable planes were also calculated and are reported in Table 2. It can be seen that the sites on (110) and (111) interact with the two probe molecules as strongly as with corner defect on the (100) plane and better than with steps. 
Those strongly basic sites may thus act as active sites in the two model reactions if they are stabilized by surface partial hydroxylation and if the reaction rate is determined by the deprotonation step. Nevertheless those transient strong basic sites cannot explain the peculiar reactivity of $\mathrm{MBOH}$ on hydroxylated surfaces because the $\mathrm{MBOH}$ conversion does not exhibit any volcano behavior upon dehydroxylation but a continuous deactivation. That suggests that the rate of $\mathrm{MBOH}$ conversion is not determined by the deprotonation step and that the surface hydroxyl groups play a specific role in the mechanism. That role of hydroxyls should be further investigated with DFT modelling of the pathways.

\section{Conclusion}

From this mixed experimental - theoretical study of the effect of natural adsorbates on the basic reactivity of $\mathrm{MgO}$, it may be concluded the following:

- The influence of carbonates and of hydroxyl groups on the surface is different. Carbonates poison the basic reactivity while a partially hydroxylated surface is more active than a bare one whatever the model reaction. Thus, the behavior of hydroxyl group cannot be generalized directly to other weak bases.

- The active sites are different between the two reactions, in line with the acidic strength of the reactant. Thus $\mathrm{MBOH}$ conversion can occur on partially carbonated steps that are able to deprotonate alcohols but it is not the case for hept-1-ene conversion. On carbonated surfaces, the treatment temperature (temp) necessary to observe a conversion is thus linked to the adsorption energy of $\mathrm{CO}_{2}$ on the defect able to deprotonate each molecule.

- In the case of hydroxylated surfaces, a maximum of activity is observed in the case of hept-1ene conversion for a partial hydroxylation, obtained after hydroxylation and desorption temperature between 700 and $800 \mathrm{~K}$. That maximum could be explained by transient stabilization of unstable active sites with the help of surface hydroxyls: hydroxyl groups can 
stabilize unstable $\mathrm{MgO}$ planes as (111) or (110) that are able to interact strongly with alkenes. Those planes are proposed as strongly active sites for hept-1-ene isomerization. In the former results obtained for $\mathrm{MBOH}$ conversion reaction, no maximum of activity was observed upon decreasing the $\mathrm{OH}$ coverage: the activity decreased continuously with increasing treatment temperature (temp) on the temperature range investigated. The unstable planes are also able to deprotonate alcohols but may stabilize them too much to allow them to react further. A specific interaction between surface $\mathrm{OH}$ groups and the alcohol may also occur and calculations are undergoing to investigating that postulated specific mechanism.

Acknowledgment: This work was granted access to the HPC resources of [CCRT/CINES/IDRIS] under the allocation 2011 [x2012086395] made by GENCI (Grand Equipement National de Calcul Intensif). Céline Chizallet and Frederik Tielens are warmly thanked for their interest and fruitful discussions.

\section{References}

1. G. A. H. Mekhemer, S. A. Halawy, M. A. Mohamed, and M. I. Zaki, The Journal of Physical Chemistry B, 2004, 108, 13379-13386.

2. A. O. Menezes, P. S. Silva, E. Padron Hernandez, L. E. P. Borges, and M. A. Fraga, Langmuir, 2009, 26, 3382-3387.

3. D. Cornu, H. Guesmi, J.-M. Krafft, and H. Lauron-Pernot, The Journal of Physical Chemistry $C, 2012,116,6645-6654$.

4. H. Kwon and D. G. Park, Bulletin of the Korean Chemical Society, 2009, 30, 2567-2573.

5. C. A. Ferretti, S. Fuente, R. Ferullo, N. Castellani, C. R. Apesteguía, and J. I. Di Cosimo, Applied Catalysis A: General, 2012, 413-414, 322-331.

6. A. Auroux and A. Gervasini, The Journal of Physical Chemistry, 1990, 94, 6371-6379. 
7. F. Audry, P. E. Hoggan, J. Saussey, J. C. Lavalley, H. Lauron-Pernot, and A. M. Le Govic, Journal of Catalysis, 1997, 168, 471-481.

8. M.-L. Bailly, C. Chizallet, G. Costentin, J.-M. Krafft, H. Lauron-Pernot, and M. Che, Journal of Catalysis, 2005, 235, 413-422.

9. V. K. Díez, C. A. Ferretti, P. A. Torresi, C. R. Apesteguía, and J. I. Di Cosimo, Catalysis Today, 2011, 173, 21-27.

10. H. Guesmi, D. Costa, D. Berthomieu, and P. Massiani, The Journal of Physical Chemistry C, 2011, 115, 5607-5618.

11. H. Guesmi and P. Massiani, Catalysis Today, 2011, 177, 25-30.

12. J. C. Lavalley, Catalysis Today, 1996, 27, 377-401.

13. C. Chizallet, H. Petitjean, G. Costentin, H. Lauron-Pernot, J. Maquet, C. Bonhomme, and M. Che, Journal of Catalysis, 2009, 268, 175-179.

14. G. W. Haas, D. E. Giblin, and M. L. Gross, International Journal of Mass Spectrometry and Ion Processes, 1998, 172, 25-46.

15. G. I. Mackay, M. H. Lien, A. C. Hopkinson, and D. K. Bohme, Canadian Journal of Chemistry, 1978, 56, 131-140.

16. H. Handa, Y. Fu, T. Baba, and Y. Ono, Characterization of strong solid bases by test reactions, Springer Netherlands, 1999, vol. 59.

17. H. Lauron-Pernot, Catalysis Reviews, 2006, 48, 315-361.

18. J.-L. Lemberton, G. Perot, M. Guisnet, and R. Maurel, Bulletin de la Société chimique de France, 1976, 3-4, 357-361

19. C.-M. Wang, Y.-D. Wang, J. Dong, S. Liu, and Z.-K. Xie, Computational and Theoretical Chemistry, 2011, 974, 52-56.

20. C. Chizallet, G. Costentin, M. Che, F. Delbecq, and P. Sautet, The Journal of Physical Chemistry B, 2006, 110, 15878-15886.

21. M.-L. Bailly, G. Costentin, H. Lauron-Pernot, J. M. Krafft, and M. Che, The journal of physical chemistry. B, 2005, 109, 2404-13.

22. H. Hattori, Chemical Reviews, 1995, 95, 537-558.

23. G. Kresse and J. Hafner, Physical Review B, 1993, 47, 558-561.

24. G. Kresse and J. Furthmüller, Computational Materials Science, 1996, 6, 15-50.

25. J. P. Perdew, K. A. Jackson, M. R. Pederson, D. J. Singh, and C. Fiolhais, Physical Review B, 1992, 46, 6671-6687. 
26. H. Petitjean, K. Tarasov, F. Delbecq, P. Sautet, J. M. Krafft, P. Bazin, M. C. Paganini, E. Giamello, M. Che, H. Lauron-Pernot, and G. Costentin, The Journal of Physical Chemistry C, 2010, 114, 3008-3016.

27. P. Geysermans, F. Finocchi, J. Goniakowski, R. Hacquart, and J. Jupille, Physical chemistry chemical physics : PCCP, 2009, 11, 2228-33.

28. R. Hacquart and J. Jupille, Journal of Crystal Growth, 2009, 311, 4598-4604.

29. V. E. Henrich, Surface Science, 1976, 57, 385-392.

30. C. A. Cadigan, A. R. Corpuz, F. Lin, C. M. Caskey, K. B. H. Finch, X. Wang, and R. M. Richards, Catalysis Science \& Technology, 2013, 3, 900.

31. H. Hattori, Applied Catalysis A: General, 2001, 222, 247-259.

32. M. F. Hoq, I. Nieves, and K. J. Klabunde, Journal of Catalysis, 1990, 123, 349-363.

33. J. L. Lemberton, G. Perot, and M. Guisnet, Journal of Catalysis, 1984, 89, 69-78.

34. H. Hattori and A. Satoh, Journal of Catalysis, 1976, 45, 32-40.

35. R. F. W. Bader, Atoms in molecules: a quantum theory, Clarendon Press, 1994.

36. F. Tielens, Journal of Molecular Structure: THEOCHEM, 2009, 903, 23-27.

37. M. Calatayud, F. Tielens, and F. De Proft, Chemical Physics Letters, 2008, 456, 59-63.

38. G. Pacchioni, A. Clotet, and J. M. Ricart, Surface Science, 1994, 315, 337-350.

39. G. Pacchioni, J. M. Ricart, and F. Illas, Journal of the American Chemical Society, 1994, 116, 10152-10158.

40. D. Spagnoli, J. P. Allen, and S. C. Parker, Langmuir: the ACS journal of surfaces and colloids, 2011, 27, 1821-9.

41. E. Carrasco, M. A. Brown, M. Sterrer, H.-J. Freund, K. Kwapien, M. Sierka, and J. Sauer, The Journal of Physical Chemistry C, 2010, 114, 18207-18214. 


\section{Tables}

Table 1

\begin{tabular}{|c|c|c|c|c|}
\hline Face & Type of defect & Nomenclature & Desorption temperature & $\begin{array}{c}\text { Desorption on DRIFT } \\
\text { spectra }\end{array}$ \\
\hline \multirow{2}{*}{$(100)$} & $\begin{array}{c}\text { Corner, Kink; } \\
\text { Divacancy }\end{array}$ & $\begin{array}{c}\text { B-C3, B-K, B- } \\
\text { D }\end{array}$ & $822>\mathrm{T}>722$ & $873>\mathrm{T}>673 \mathrm{~K}$ \\
\cline { 2 - 5 } & Step & T-S1 T-S2 & 908 & $\mathrm{~T}>873 \mathrm{~K}$ \\
\hline
\end{tabular}

Description of the carbonates on the $\mathrm{MgO}$ surface, from ref. ${ }^{3}$. The letters $\mathrm{B}$ and $\mathrm{T}$ refer to the « bidentate $»$ and $\ll$ tridentate carbonates.

Table 2

\begin{tabular}{|c|c|c|c|c|c|c|c|}
\hline Plane & \multicolumn{5}{|c|}{$(100)$} & $(110)$ & $(111)$ \\
\hline Site & Terrace & Step & Corner & Divacancy & Kink & & \\
\hline $\mathrm{E}_{\text {ads }}($ butene) $(\mathrm{eV})$ & $-0.08(\mathrm{U})$ & $-0.28(\mathrm{U})$ & $-0.34(\mathrm{D})$ & $-0.52(\mathrm{D})$ & $-0.55(\mathrm{D})$ & $-0.32(\mathrm{U})$ & $-1.40(\mathrm{D})$ \\
\hline $\mathrm{E}_{\text {ads }}(\mathrm{MeOH})(\mathrm{eV})$ & $-0.50(\mathrm{U})$ & $-1.86(\mathrm{D})$ & $-1.60(\mathrm{D})$ & $-3.81(\mathrm{D})$ & $-2.48(\mathrm{D})$ & $-2.54(\mathrm{D})$ & Not stable \\
\hline
\end{tabular}

D stands for "dissociated" and U for "undissociated"

Calculated adsorption energy of butene and methanol on various planes and defects. The data concerning the adsorption of $\mathrm{MeOH}$ on (100) plane and defects come from ref. 27 
Table 3

\begin{tabular}{|c|c|c|}
\hline Defect & Number of hydroxyl groups & Adsorption energy (eV) \\
\hline \multirow{2}{*}{ Step } & 0 & $-0.28(\mathrm{U})$ \\
\cline { 2 - 3 } & 2 & $-0.21(\mathrm{U})$ \\
\hline \multirow{2}{*}{ Kink } & 0 & $-0.55(\mathrm{D})$ \\
\cline { 2 - 3 } & 2 & -0.50 (D) \\
\hline
\end{tabular}

D stands for "dissociated" and U for "undissociated"

Adsorption energy of but-1-ene on hydroxylated and non-hydroxylated defects. 


\section{Figure captions:}

Figure 1: Schematic presentation of the two considered model reactions: a) the isomerization of hept1-ene, b) the conversion of $\mathrm{MBOH}$. Acidic proton is represented in bold.

Figure 2: Pretreatment protocol showing flows and temperatures conditions used to get a surface with various carbonate or hydroxyl coverage

Figure 3: Conversion of the carbonated surface of magnesium oxide in the two model reactions. Reaction temperatures are fixed to $333 \mathrm{~K}$ for Hep-1-ene and $393 \mathrm{~K}$ for $\mathrm{MBOH}$.

Figure 4: Conversion of the hydroxylated surface in the isomerization of hept-1-ene. Reaction temperature is fixed to $333 \mathrm{~K}$.

Figure 5: Desorption temperature of the $\mathrm{CO}_{2}$ (from ${ }^{3}$ )on various sites and their ability to deprotonate acids.

Figure 6: DFT optimized geometries of the adsorbed but-1-ene interacting with various $\mathrm{MgO}$ sites

Figure 7: Step of the MgO (100) surface with a 2/3 monolayer coverage of carbonates. With such a coverage, the two $\mathrm{Mg}_{4 \mathrm{c}}$ surrounding the only free $\mathrm{O}_{4 \mathrm{c}}$ of the surface (green arrow) are already engaged in ionic and covalent bonding with other carbonate. These cations cannot stabilize the conjugated base of a Brønsted acid.

Figure 8: Possible mechanism for the isomerization involving an hydroxyl group and an oxygen ion.

Figure 9: DFT optimized geometries of the adsorbed but-1-ene interacting with hydroxylated and nonhydroxylated step

Figure 10: Electric field maps around the $\mathrm{MgO}$ surface in presence and absence of $\mathrm{OH}$ groups. The arrows indicates the surface oxygen atoms of the edge step free from dissociated $\mathrm{H}_{2} \mathrm{O}$ molecule. 
Figure 11: DRIFT spectra of the magnesium oxide after $\mathrm{CO}_{2}$ addition and heating on a partially hydroxylated (solid line) and dehydroxylated (dashed line) surfaces. 
Figure 1

a

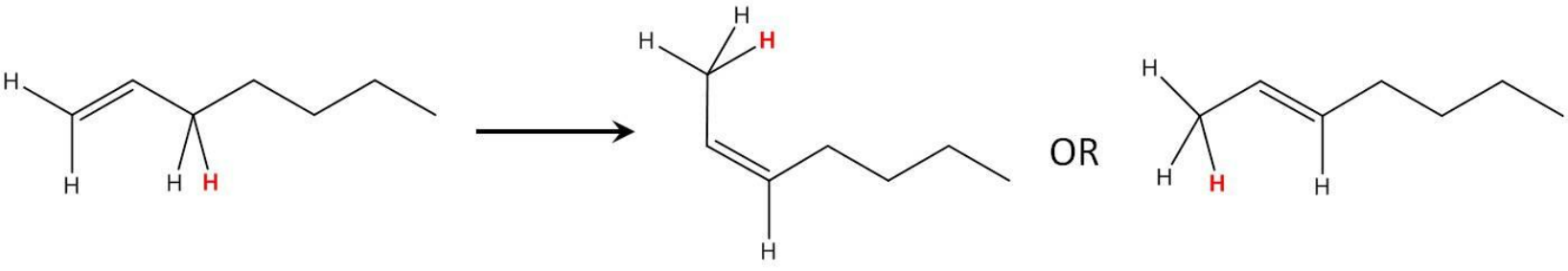

b<smiles>C#CC(C)(C)O</smiles><smiles>CC</smiles><smiles>CC(C)=O</smiles>

$+$<smiles>C#CN</smiles> 
Figure 2

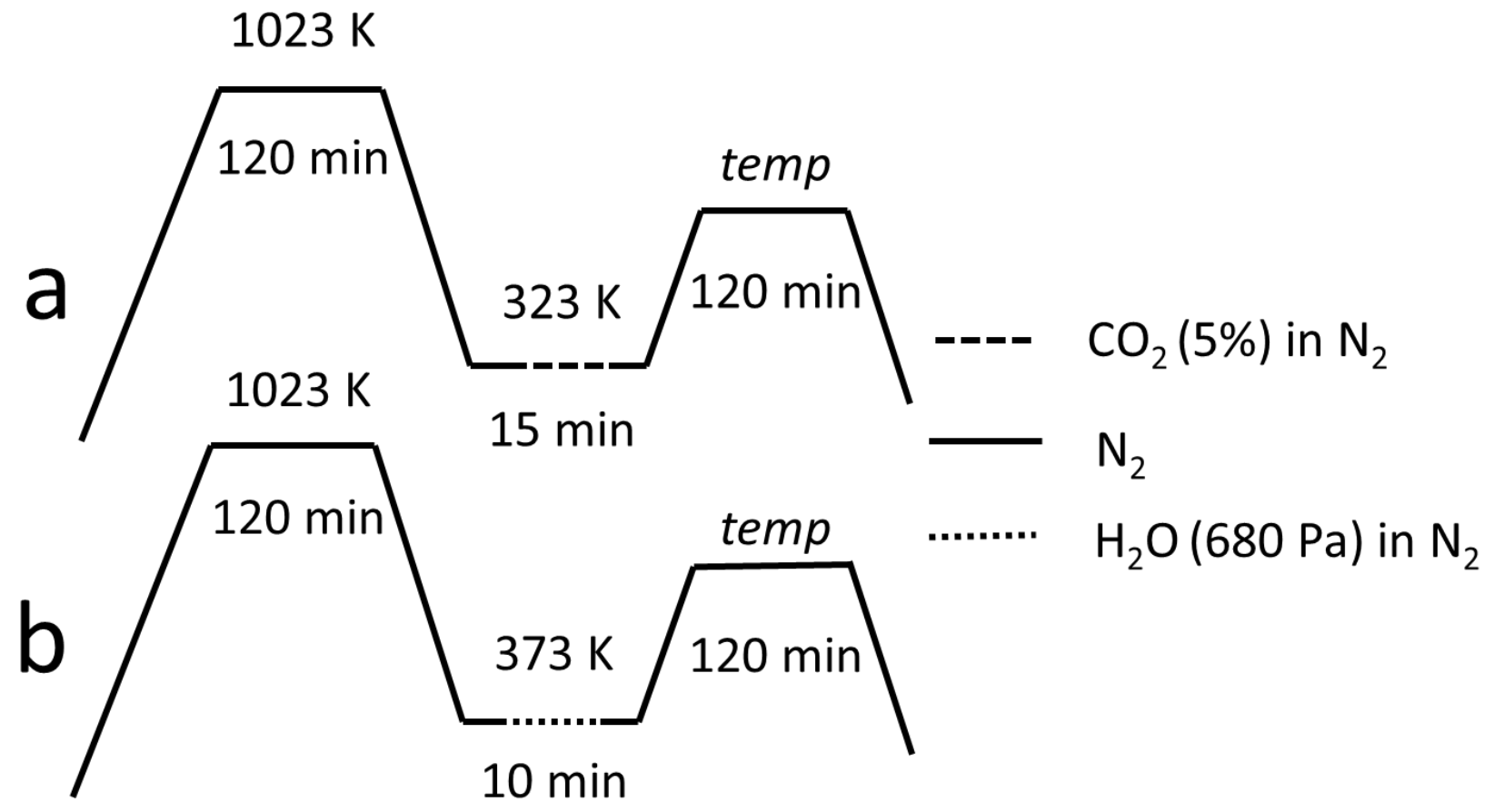


Figure 3

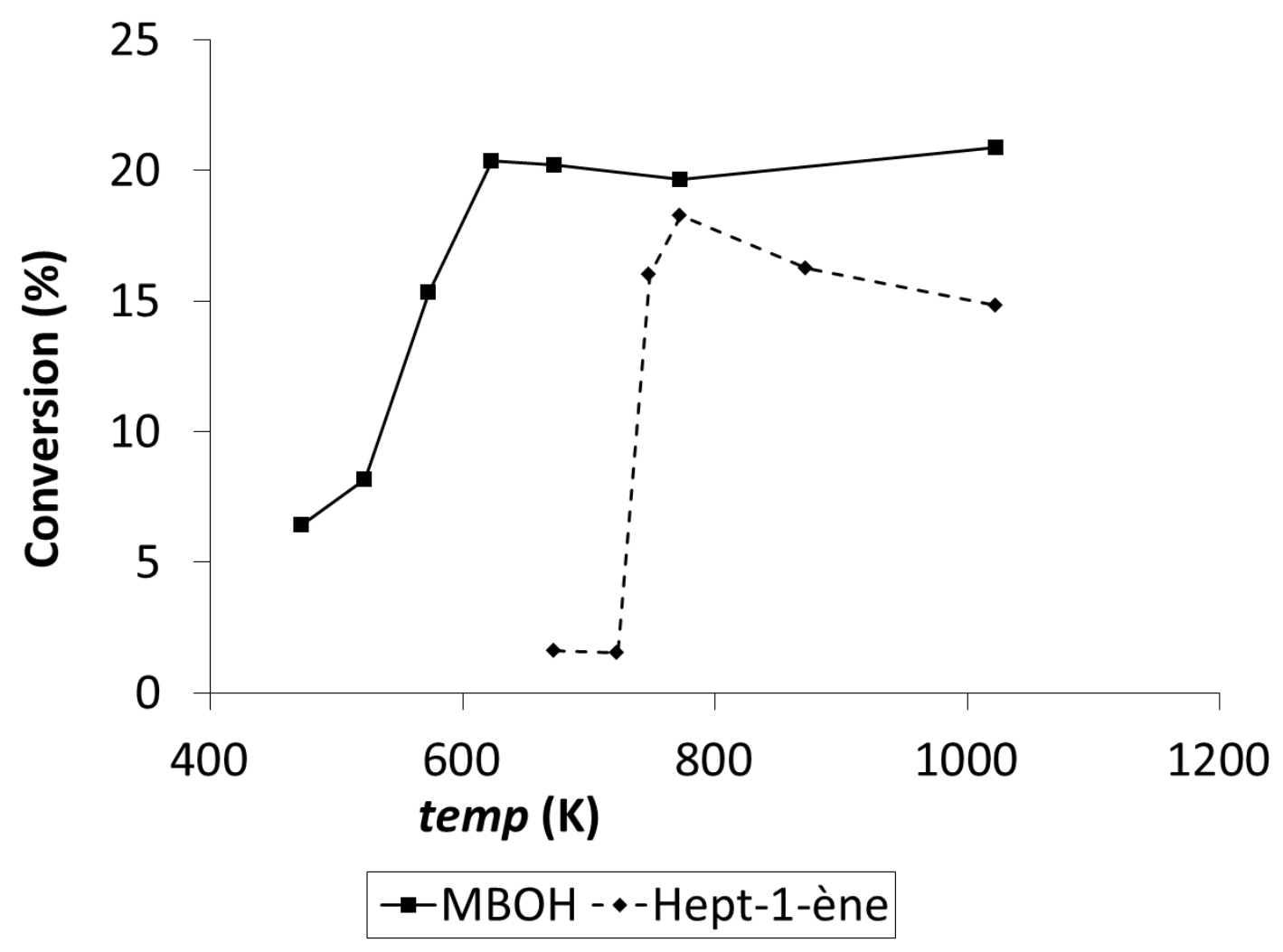


Figure 4

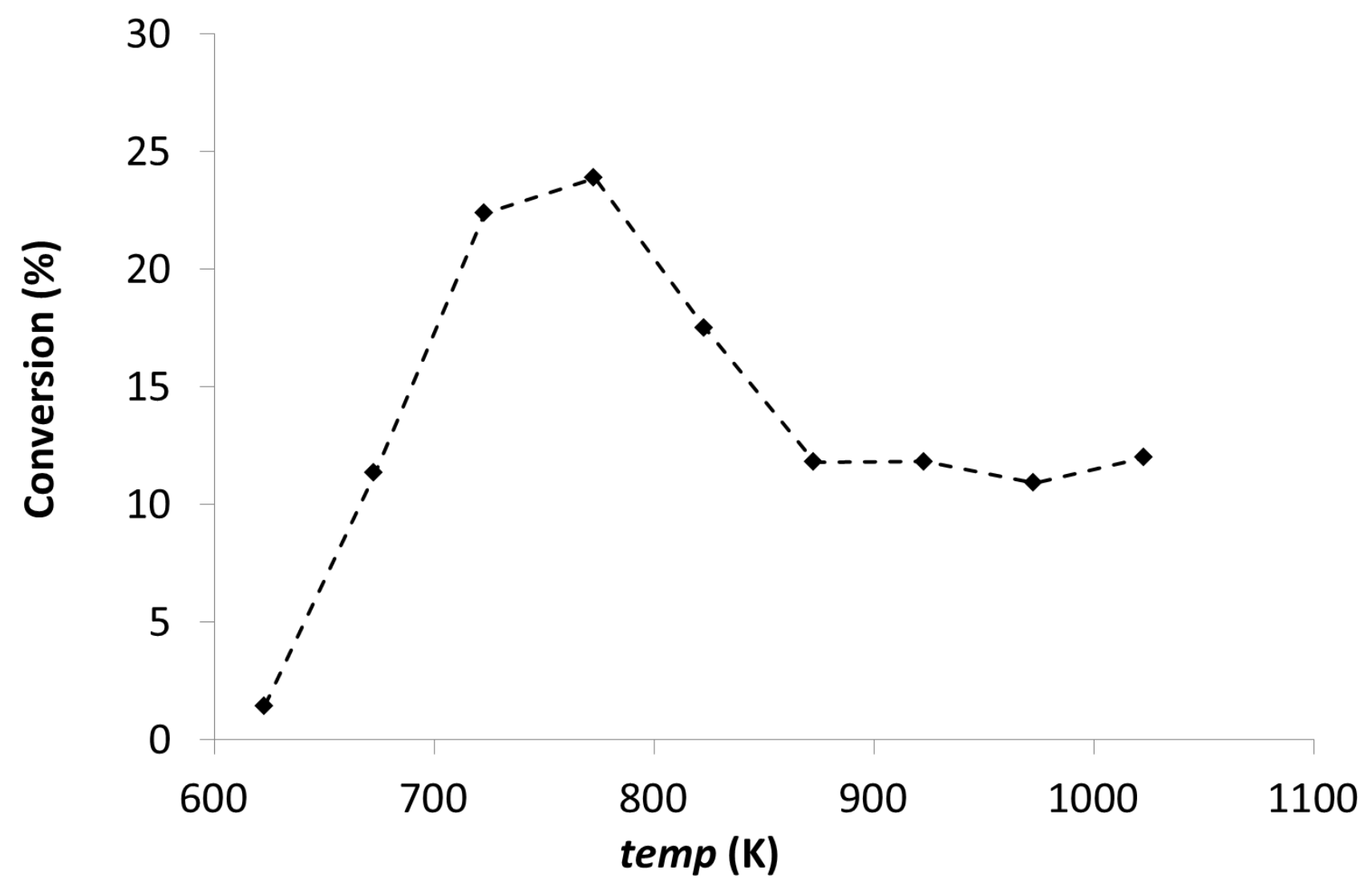


Figure 5

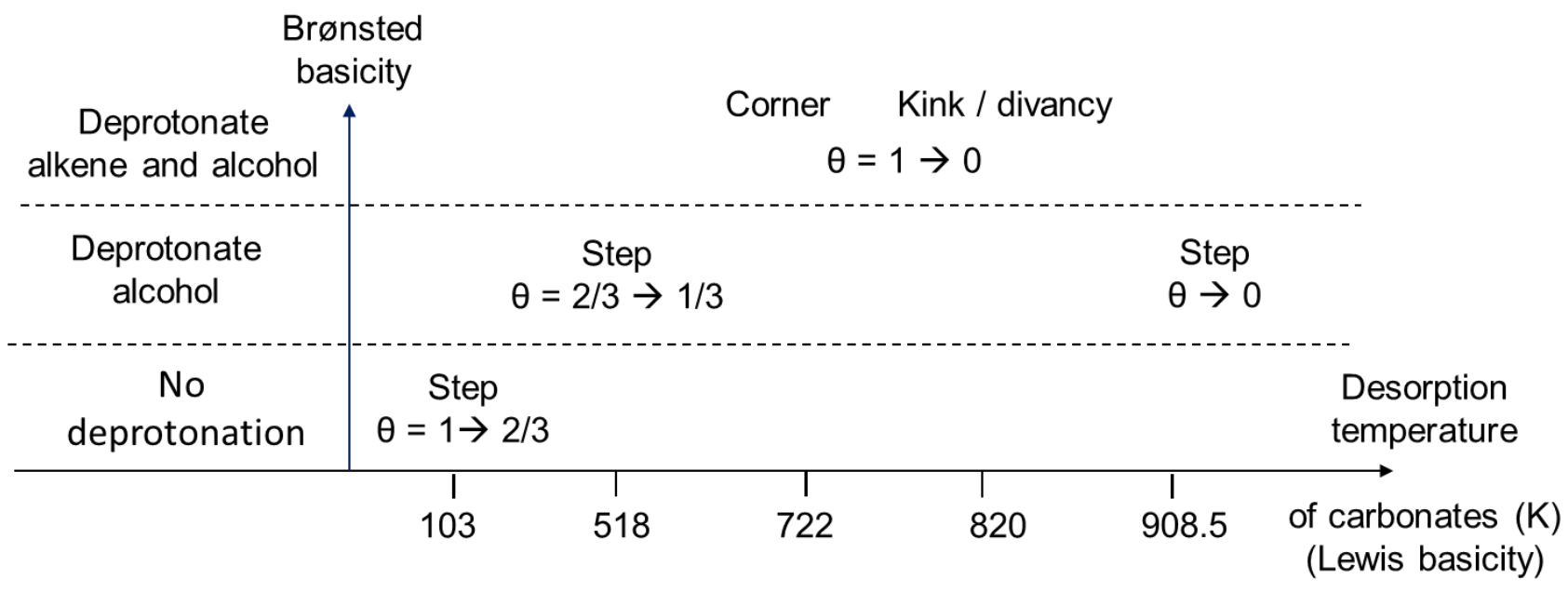


Figure 6

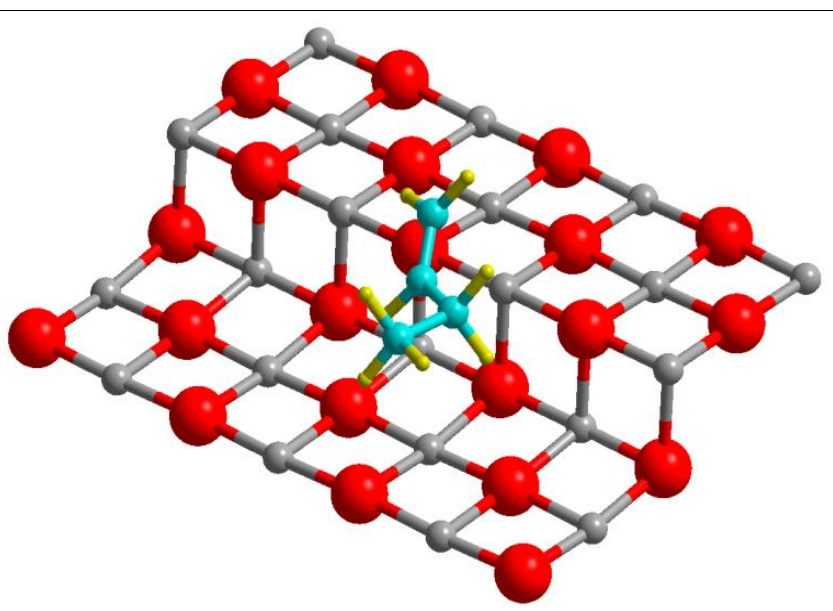

a) Monoatomic step (ND)

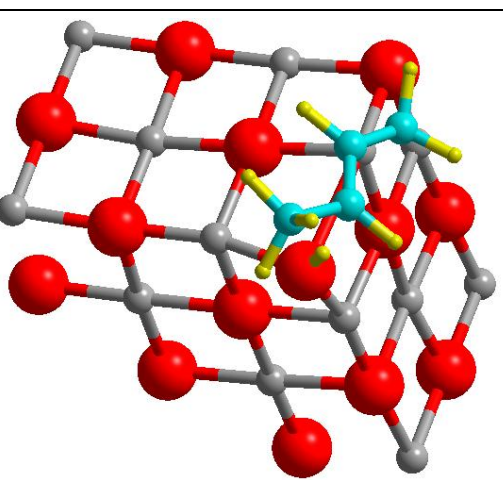

c) Corner terminated by $\mathrm{O}(\mathrm{D})$

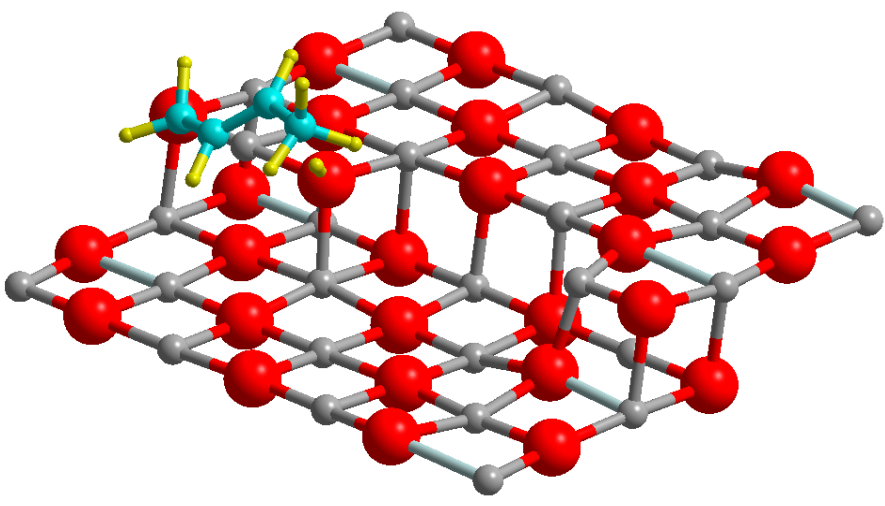

e) Divacancy (D)

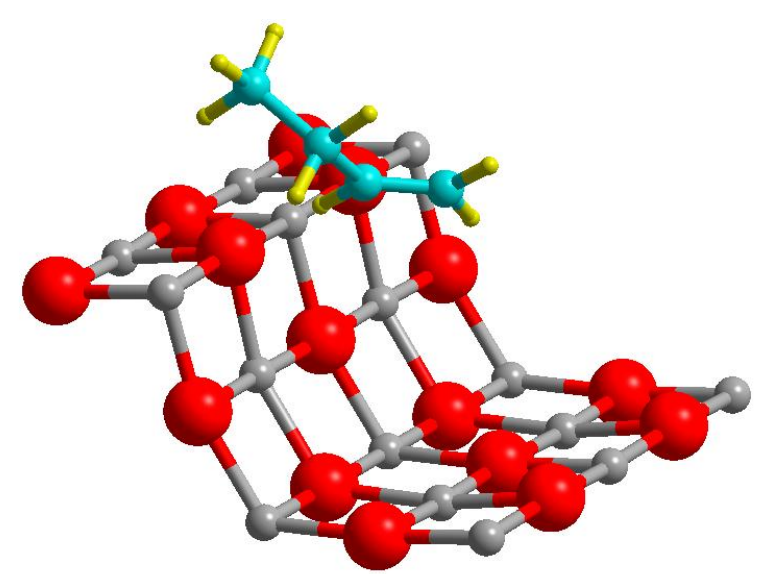

b) Diatomic step (ND)

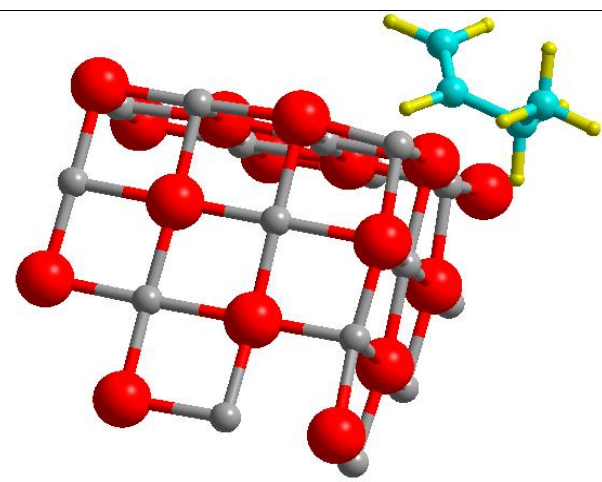

d) Corner terminated by a $\mathrm{Mg}(\mathrm{ND})$

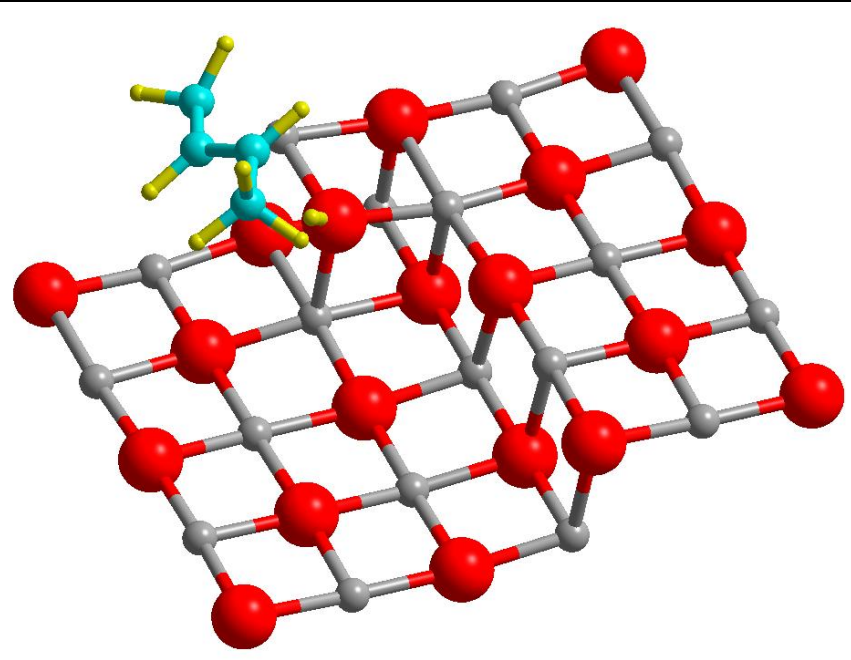

f) Kink (D)

ND: not dissociated, D dissociated

But-1-ene adsorbed on various defects of the (100) plane 
Figure 7

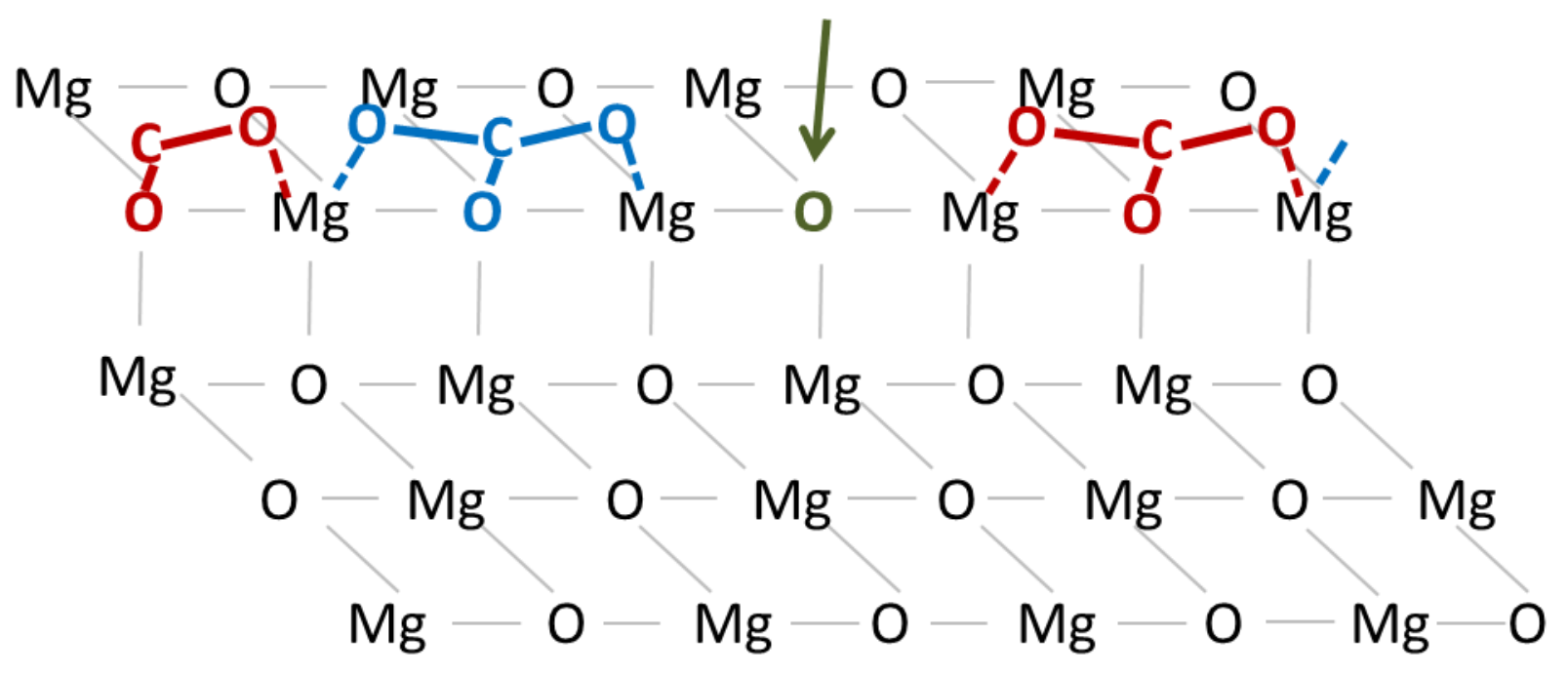


Figure 8

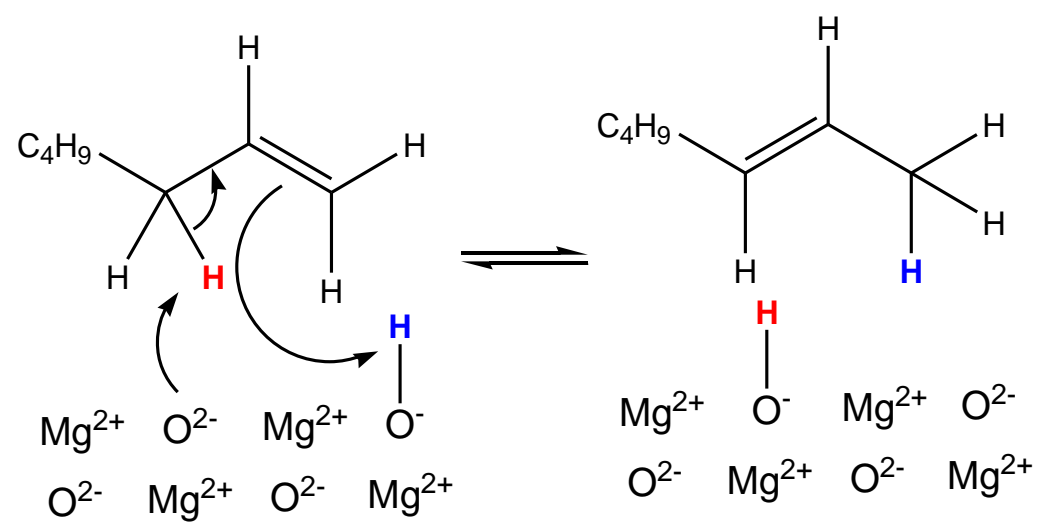


Figure 9
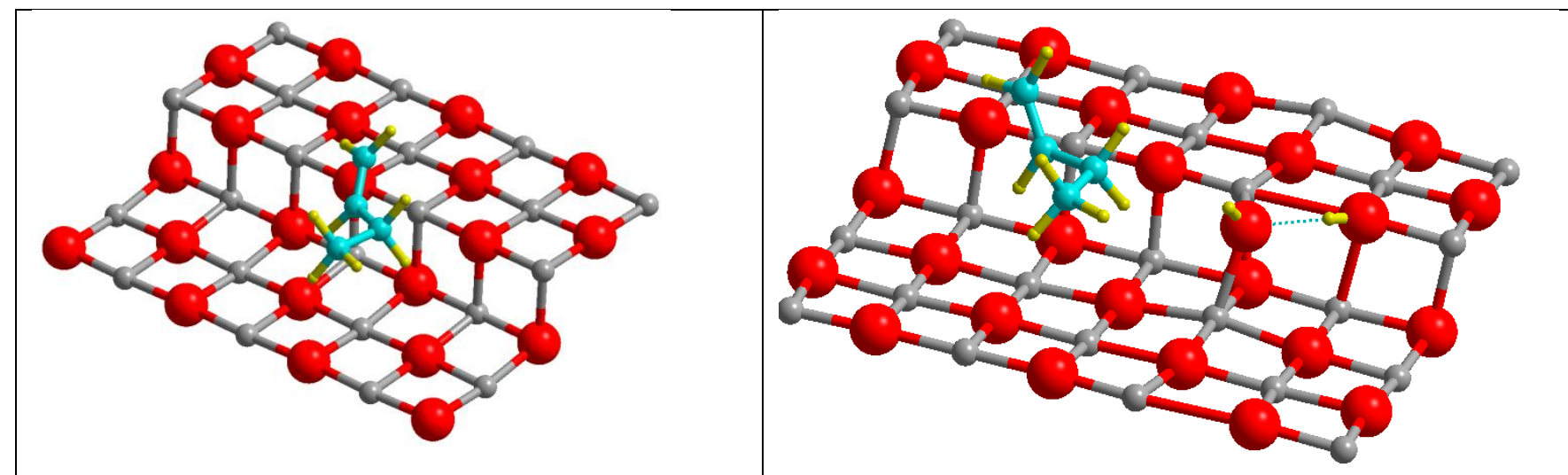

a) Not hydroxylated monoatomic step (ND)

b) Partially hydroxylated monatomic step 
Figure 10

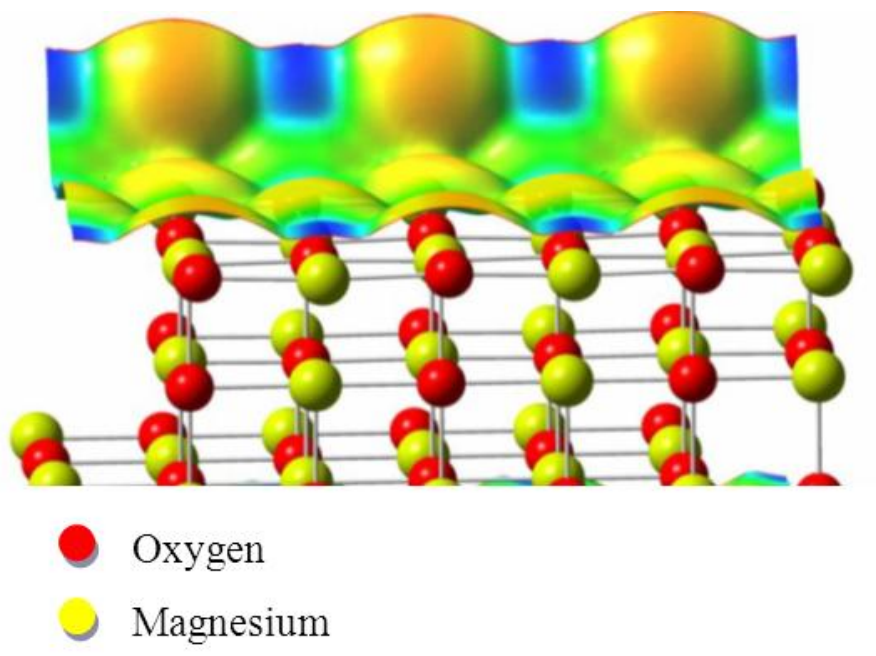

Electric potential (arbitrary value)

Without OH

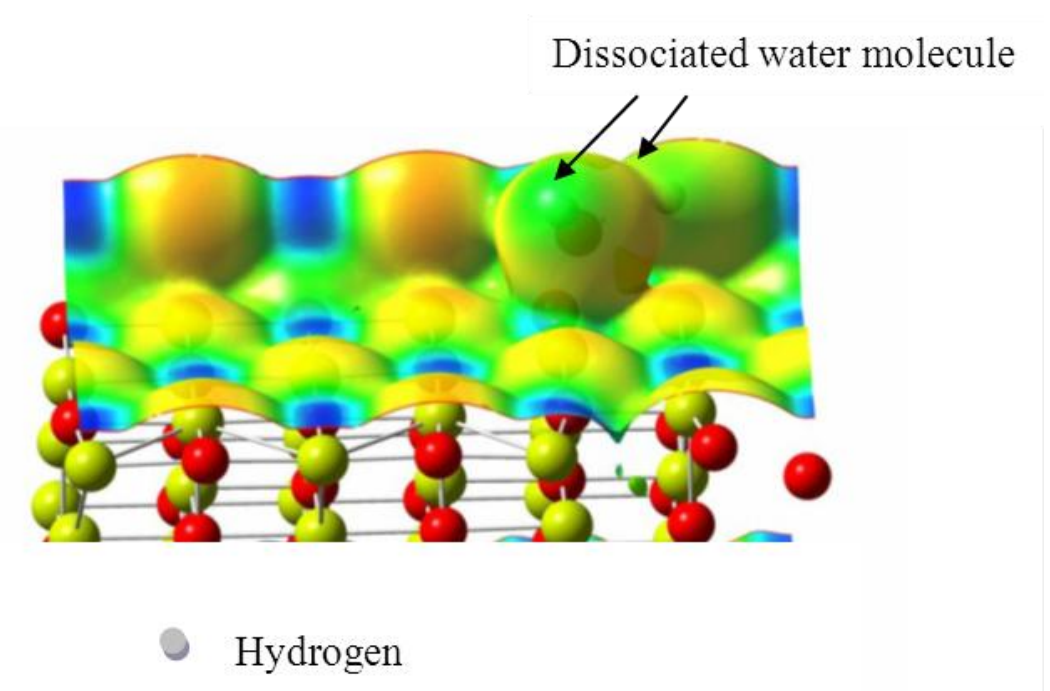

Electric potential (arbitrary value)

\section{With OH}


Figure 11

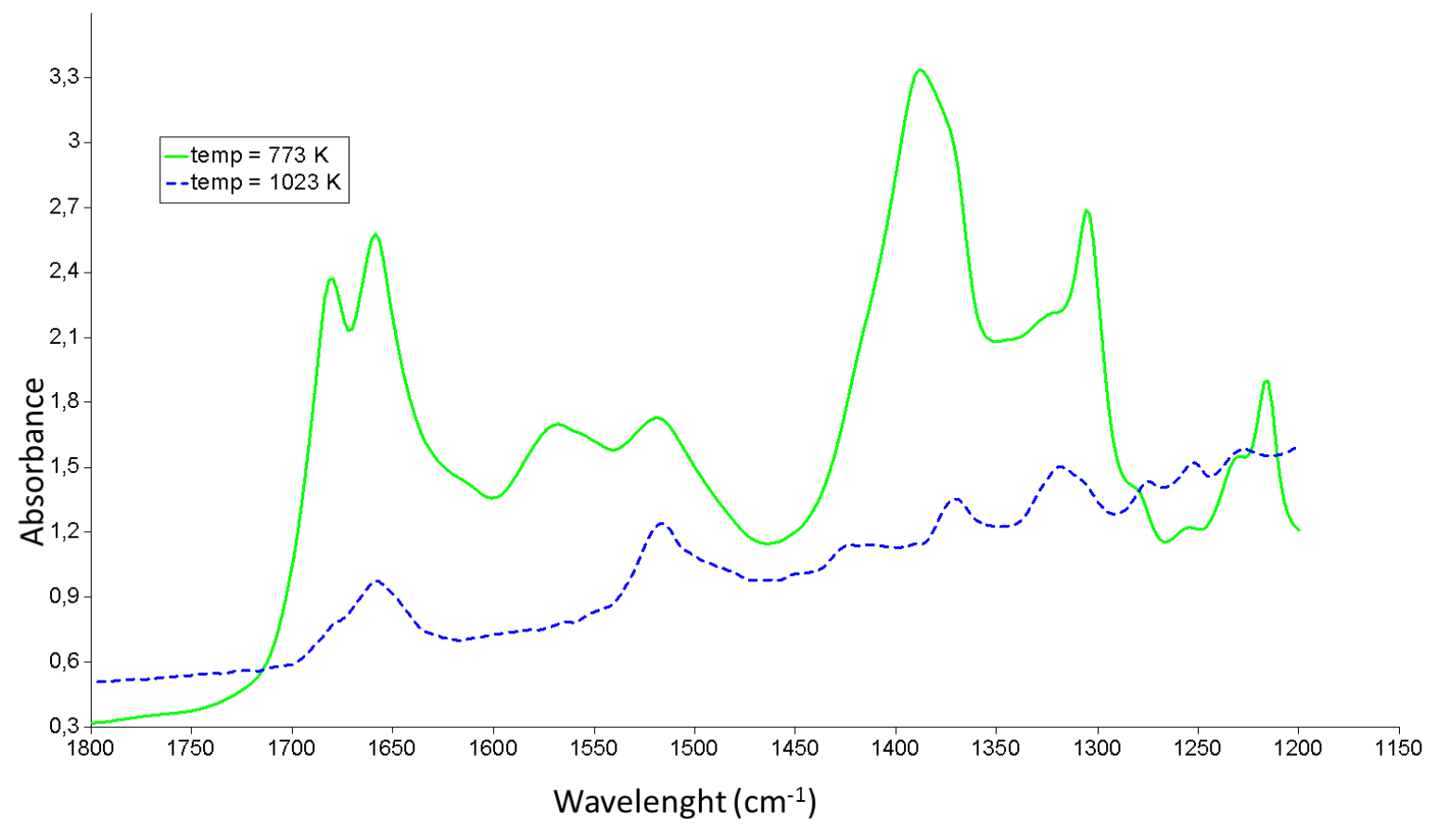

